\title{
Delimitation of the Thoracosphaeraceae (Dinophyceae), Including the Calcareous Dinoflagellates, Based on Large Amounts of Ribosomal RNA Sequence Data
}

\author{
Marc Gottschling ${ }^{\mathrm{a}, 1}$, Sylvia Soehnera ${ }^{\mathrm{a}}$ Carmen Zinssmeister ${ }^{\mathrm{a}}$, Uwe John ${ }^{\mathrm{b}}$, \\ Jörg Plötnerc, Michael Schweikert ${ }^{d}$, Katerina Aligizaki ${ }^{\mathrm{e}}$, and Malte Elbrächter ${ }^{f}$
}

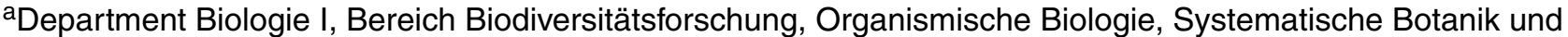
Mykologie, Ludwig-Maximilians-Universität München, GeoBio-Center, Menzinger Str. 67, 80638 Munich, Germany

${ }^{b}$ Department Chemical Ecology, Alfred Wegener Institute for Polar and Marine Research, Bremerhaven, Germany

cMuseum für Naturkunde, Leibniz-Institut für Evolutions- und Biodiversitätsforschung an der Humboldt-Universität Berlin, Berlin, Germany

${ }^{\mathrm{d} B i o l o g i s c h e s ~ I n s t i t u t ~-~ A b t e i l u n g ~ Z o o l o g i e, ~ U n i v e r s i t a ̈ t ~ S t u t t g a r t, ~ S t u t t g a r t, ~ G e r m a n y ~}$

eDepartment of Botany, School of Biology, Aristotle University of Thessaloniki, Thessaloniki, Greece

fWattenmeerstation Sylt, Alfred Wegener Institute for Polar and Marine Research, List/Sylt, Germany
}

Submitted November 4, 2010; Accepted May 21, 2011

Monitoring Editor: Hervé Philippe

The phylogenetic relationships of the Dinophyceae (Alveolata) are not sufficiently resolved at present. The Thoracosphaeraceae (Peridiniales) are the only group of the Alveolata that include members with calcareous coccoid stages; this trait is considered apomorphic. Although the coccoid stage apparently is not calcareous, Bysmatrum has been assigned to the Thoracosphaeraceae based on thecal morphology. We tested the monophyly of the Thoracosphaeraceae using large sets of ribosomal RNA sequence data of the Alveolata including the Dinophyceae. Phylogenetic analyses were performed using Maximum Likelihood and Bayesian approaches. The Thoracosphaeraceae were monophyletic, but included also a number of non-calcareous dinophytes (such as Pentapharsodinium and Pfiesteria) and even parasites (such as Duboscquodinium and Tintinnophagus). Bysmatrum had an isolated and uncertain phylogenetic position outside the Thoracosphaeraceae. The phylogenetic relationships among calcareous dinophytes appear complex, and the assumption of the single origin of the potential to produce calcareous structures is challenged. The application of concatenated ribosomal RNA sequence data may prove promising for phylogenetic reconstructions of the Dinophyceae in future. (C) 2011 Elsevier GmbH. All rights reserved.

Key words: Calcareous dinoflagellates; ITS; LSU; molecular systematics; morphology; rRNA; SSU.

1Corresponding author; fax +4989172638
e-mail gottschling @ bio.Imu.de (M. Gottschling). 


\section{Introduction}

Genes and spacers of the ribosomal RNA (rRNA) operon are among the most widely used genetic loci to reconstruct the entire Tree of Life as well as phylogenies of many particular organismal groups. Among unicellular eukaryotic life forms, molecular phylogenies using different rRNA sequences are particularly numerous among the alveolates, including the Dinophyceae (Daugbjerg et al. 2000; Gottschling et al. 2005a; John et al. 2003; Kremp et al. 2005; Saldarriaga et al. 2004), with more than 2,000 extant species described. Being as well primary producers and predators in marine and fresh water environments makes the Dinophyceae with their impact on carbon fixation an important part of the global aquatic ecosystem.

Dinophyceae exhibit many types of life style and nutrition, beside the phototroph and mixotroph forms. Some species are endosymbionts of marine animals and protozoa and contribute to the formation of coral reefs, while approximately $10 \%$ of the known species are parasitic. Together with the Ciliata and Apicomplexa (= Sporozoa), the Dinophyceae belong to the Alveolata and are a well-supported monophyletic group based on both molecular data and many apomorphies. Compared to all other eukaryotes, the genome of the Dinophyceae is highly unusual with respect to structure and regulation (reviewed by Moreno Díaz de la Espina et al. 2005). The nucleus contains chromosomes that are permanently condensed throughout the cell cycle except during DNA replication (Dodge 1966), displaying a liquid crystalline state (Rill et al. 1989). Morphologically, the Dinophyceae exhibit unique traits such as the coiled transverse flagellum associated with a transverse groove termed the 'cingulum' (Fensome et al. 1999; Harper et al. 2005; Leander and Keeling 2004; Rizzo 2003; Taylor 1980).

Using molecular data, the phylogeny of the Dinophyceae is difficult to reconstruct because of multiple endosymbiosis events, lateral gene transfers, and divergent substitution rates (Bhattacharya and Nosenko 2008; Howe et al. 2008; Minge et al. 2010; Moore et al. 2008; Morden and Sherwood 2002; Saldarriaga et al. 2004; Shalchian-Tabrizi et al. 2006; Yoon et al. 2005). A considerable fraction of published Dinophyceae molecular phylogenies relies exclusively on sequences of the small subunit rRNA (SSU; app. 1,800 bp in length), although the power of this locus for evolutionary reconstructions is limited (Taylor 2004). Phylogenetic trees as inferred from nuclear ribosomal sequences show polytomies in many crucial nodes, and the application of additional genetic markers is therefore highly recommended. Multi-gene approaches (Hoppenrath and Leander 2010; Yoon et al. 2005; Zhang et al. 2007, 2008), comprising sequences not only from the nucleus but also from mitochondria and chloroplasts, provide somewhat better resolution, and this is promising for future studies of phylogeny.

The branch lengths in the phylogenetic trees of the Dinophyceae are highly unbalanced. Many sequences of groups such as the Peridiniales render rather short branches, while some Dinophyceae including Nocticula and Oxyrrhis have very long branches and an unresolved phylogenetic position. Moreover, only few groups such as the Gonyaulacales, Suessiales, and Dinophysiales constitute monophyletic groups in molecular trees, while other traditional taxonomic units including the Peridiniales and Gymnodiniales appear highly paraand polyphyletic (Kremp et al. 2005; Saldarriaga et al. 2004; Zhang et al. 2007). The Thoracosphaeraceae (Peridiniales) include all Dinophyceae that produce calcareous coccoid stages during their development (important taxa are Calcicarpinum, Scrippsiella, and Thoracosphaera) as well as some (presumably secondarily) non-calcareous relatives such as Pentapharsodinium and Pfiesteria (Elbrächter et al. 2008). The monophyly of the Thoracosphaeraceae has not been shown in all previous phylogenetic studies, but this might be primarily because of the generally poor resolution of molecular trees in the Dinophyceae. They appear, however, to constitute a natural group in some studies, despite either limited molecular data (only sequences of the Internal Transcribed Spacer, ITS: Gottschling et al. 2005a) and/or a limited taxon sample (Tillmann et al. 2009; Zhang et al. 2007). The hypothesis that the Thoracosphaeraceae are monophyletic remains thus to be rigorously tested.

Currently comprising five species, Bysmatrum has been previously assigned to the Thoracosphaeraceae based on thecal morphology. The name has been introduced for benthic scrippsielloid algae (Faust and Steidinger 1998), since most of the motile stages of Scrippsiella share planktonic life forms. Moreover, both taxa differ in their morphologies: In Bysmatrum, plate $3^{\prime}$ separates the intercalary plates $2 a$ and $3 a$ and has a variously vermiculate to reticulate theca (Faust and Steidinger 1998; Murray et al. 2006; Ten-Hage et al. 2001). In contrast, plates $2 a$ and $3 a$ do always contact in Scrippsiella, and the theca is smooth without any ornamental structures (D'Onofrio et al. 1999; Gottschling et al. 2005b; Montresor et al. 2003). 

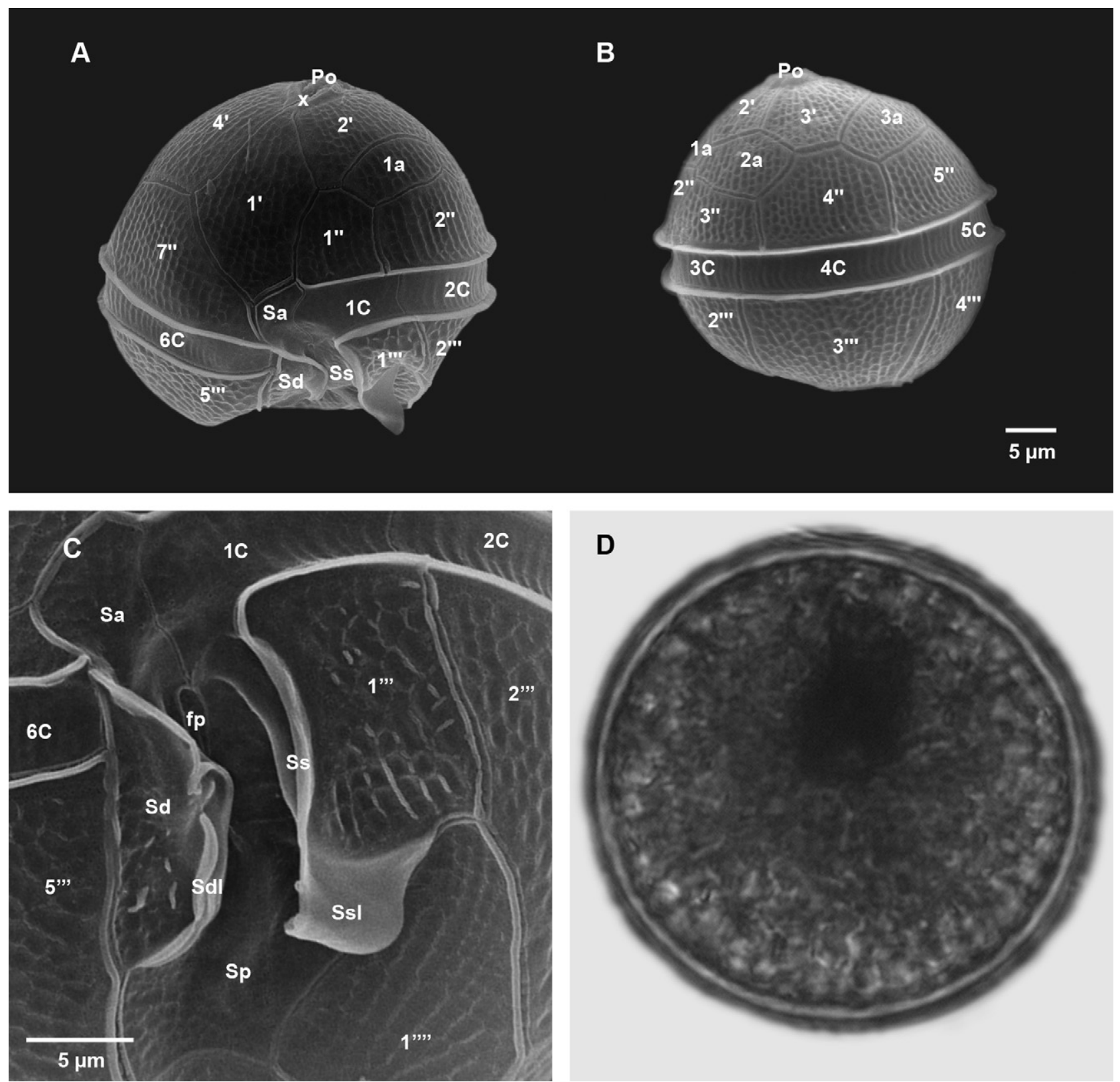

Figure 1. Bysmatrum had a peridinean tabulation pattern. Scanning electron microscope (SEM; Fig. 1A-C) and light microscope images (Fig. 1D) of Bysmatrum. A: Ventral view of epitheca, cingulum, and parts of hypotheca and sulcal region. B: Dorsal view of the thecate cell, the intercalary plates $2 a$ and $3 a$ were separated by plates $3^{\prime}$ and $4^{\prime \prime}$. C: Detail of the sulcal region with 4 sulcal plates and well developed lists (Sdl and Ssl) at the plates Sd and 1"'. D: Non-calcified coccoid stage (without scale bar, image taken at x400). Abbreviations: $n C$, cingular plates; fp, flagellar pore (anterior or posterior flagellar pore); n', apical plates; n", precingular plates; n"', postcingular plates; n'”', antapical plates; na, anterior intercalary plates; $\mathrm{P}_{\mathrm{o}}$, apical pore plate; Sa, apical sulcal plate; Sd, right sulcal plate; Sdl, right sulcal list at plate Sd; Sp, posterior sulcal plate; Ss, left sulcal plate; Ssl, left sulcal list at plate 1"'; $x$, channel plate. 


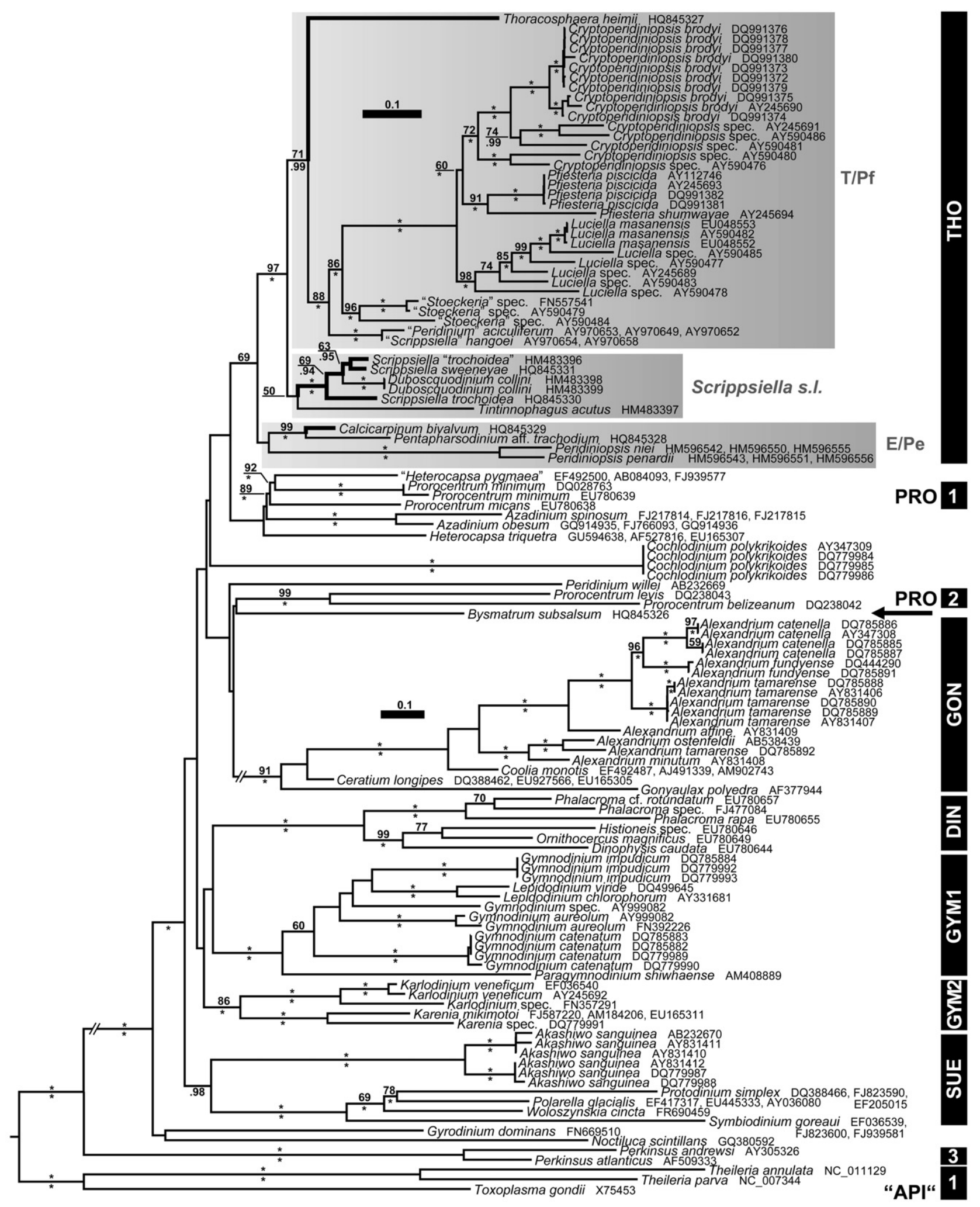


In this study, we test the hypothesis whether the Thoracosphaeraceae are monophyletic and intend to determine the phylogenetic position of Bysmatrum subsalsum, the type of Bysmatrum. To address both reliably, large molecular data sets are necessary, and we use sequences comprising the complete SSU, the 5.8S rRNA (including the ITSs), and partial sequences of the large rRNA subunit (LSU). We therefore investigate the largest taxon sample possible at present, including -to the best of our knowledge- all available Alveolata sequences spanning this genetic region. We thus also aim at a better internal resolution of Dinophyceae molecular trees as a backbone for future phylogenetic studies.

\section{Results}

\section{Morphology}

Bysmatrum subsalsum exhibited photosynthetic, armored, pentagonal through round thecate cells, 21-45 $\mu \mathrm{m}$ long and $23-47 \mu \mathrm{m}$ wide (Fig. 1A-B). The colour was golden-brown, and red-orange accumulation bodies were present in larger thecate cells. The epitheca had a hemispherical shape, and the hypotheca was round through pentagonal, showing an emargination of the sulcus together with the antapical plates. The cingulum was wide and deep. The plate ornamentation was generally reticulate, the plates Sd and 1"' were reticulate and striate, and the cingulum was transversely striate.

Thecal plate morphology of $B$. subsalsum (Fig. $1 \mathrm{~A}-\mathrm{C}$ ) corresponded to the typical peridinean pattern, consisting of 7 precingular plates, 4 sulcal plates, 5 postcingular plates, and 2 antapical plates (specific Kofoid formula: $\mathrm{P}_{0}, \mathrm{ACP}, \mathrm{X}, 4^{\prime}, 3 \mathrm{a}, 7^{\prime \prime}, 6 \mathrm{c}$, $4 \mathrm{~s}, 5^{\prime \prime \prime}, 2^{\prime \prime \prime \prime)}$. All major plates had more or less the same size, and the anterior intercalary plates $2 a$ and 3a were separated from each other by the apical plates 3' and 4". The shape of plate 1a was pentagonal, of plate $2 a$ hexagonal, and of plate 3a pentagonal. The apical plate 1' was asymmetric and pentagonal. It connected the canal plate $X$ and the anterior sulcal plate (Sa). Plate 1' was displaced to the right side between the apex and the sulcus and did not contact both in a direct line. The apical closing plate was located within the pore plate and delineated the plasma from the surrounding medium. There were four emarginated sulcal plates (Fig. 1C). The right sulcal plate (Sd) had an extensive list and almost covered the flagellar pore. Plate $1^{\prime \prime \prime}$ also showed a list antapically.

The coccoid stage of $B$. subsalsum (Fig. 1D) was not calcified, and cells were spherical through ovoid, $41-51 \mu \mathrm{m}$ in diamater. The colour was golden-brown, and a red-orange accumulation body was present.

\section{Molecular Phylogenies}

Tree topologies derived from the Alveolata alignments (Figs S1-S2, S4 in the Supplementary Material) were largely congruent, independently whether the Bayesian or the ML algorithm was applied. Many nodes showed high if not maximal statistical support values (LBS: ML support values; BPP: Bayesian posterior probabilities). Using the Ciliata as monophyletic outgroup, members of the Apicomplexa were paraphyletic, consisting of three lineages (Fig. S1 in the Supplementary Material): Cryptosporidium (100LBS, 1.00BPP), Perkinsus including an unspecified marine alveolate (99LBS, 1.00BPP), and a third large and diverse main clade (1.00BPP). Cryptosporidium was the sister group of all other Apicomplexa+Dinophyceae (although support below 50LBS and .90BPP, respectively) as well as Perkinsus of the Dinophyceae (100 LBS, 1.00BPP). The Dinophyceae were monophyletic (100LBS, 1.00BPP) and segregated in a number of lineages. One of these lineages were the Thoracosphaeraceae (including the important species of Calcicarpinum, Scrippsiella, Thoracosphaera, and Pfiesteria; 90LBS, .99BPP). Bysmatrum had a

Figure 2. The Thoracosphaeraceae were monophyletic and included both calcareous and non-calcareous forms. Maximum likelihood (ML) tree $(-\operatorname{In}=87,808)$ of 113 members of the Dinophyceae (including five new sequences of the Thoracosphaeraceae plus Bysmatrum) as inferred from a MUSCLE generated rRNA nucleotide alignment spanning the complete SSU, ITS region, and LSU domains 1 through 2 (2,286 parsimonyinformative positions). Major clades are indicated; members of the Thoracophaeraceae with known calcareous coccoid stages are highlighted by bold branches. Branch lengths are drawn to scale, with the scale bar indicating the number of nt substitutions per site. Numbers on branches are statistical support values to clusters on the right of them (above: ML bootstrap support values, values under 50 are not shown; below: Bayesian posterior probabilities, values under .90 are not shown); maximal support values are indicated by asterisks. The tree is rooted with five sequences of the Apicomplexa. Abbreviations: API1, API3: different clades of Apicomplexa; DIN: Dinophysiales; GON: Gonyaulacales; GYM1, GYM2: different clades of Gymnodiniales; PRO1, PRO2: different clades of Prorocentrales; SUE: Suessiales; THO: Thoracosphaeraceae. 
phylogenetic position outside the Thoracosphaeraceae and exhibited a close relationship on a long branch to the Gonyaulacales (.98BPP).

Tree topologies derived from the Dinophyceae alignment (Fig. 2 and Figs S3, S5-S6 in the Supplementary Material) were also largely congruent, independently whether the Bayesian or the ML algorithm was applied. Many nodes exhibited high support values, but the phylogenetic backbone and the basal nodes were only weakly resolved. The Dinophyceae were monophyletic (Fig. 2; 100LBS, 1.00BPP), and the Dinophysiales (100LBS, 1.00BPP) and Gonyaulacales (100LBS, 1.00BPP) corresponded to established systematic units among their major lineages. Several other clades and lineages of the Gymnodiniales and Prorocentrales, however, did not constitute monophyletic groups. The Peridiniales were likewise not monophyletic, and the monophyly of the Thoracophaeraceae (69LBS) was not as clearly supported as inferred from the Alveolata alignment. Internally, the Thoracosphaeraceae segregated into three lineages, namely the $\mathrm{E} / \mathrm{Pe}$-clade (marine and possibly also freshwater environments), the T/Pf-clade (71LBS, .99BPP; marine, brackish, and fresh water environments), and Scrippsiella s.l. (50LBS; marine environments), whereas the latter two clades showed a close relationship (97LBS, 1.00BPP). Bysmatrum did not nest with the Thoracosphaeraceae, and its closest relative could not be determined reliably.

Species with calcareous coccoid stages known did not constitute a monophyletic group and were scattered throughout the three clades of the Thoracosphaeraceae. In the E/Pe-clade, calcareous Calcicarpinum bivalvum and non-calcareous Pentapharsodinium aff. trachodium were closely related (99LB, 1.00BPP) and constituted the sister group of non-calcareous species assigned to Peridiniopsis. Non-calcareous and parasitic Duboscquodinium was nested within calcareous Scrippsiella, and together (100LBS, 1.00BPP) they constituted the sister group of non-calcareous and parasitic Tintinnophagus. Finally, the non-calcareous pfiesterians (i.e., Cryptoperidiniopsis, Luciella, Pfiesteria, and "Stoeckeria") plus "Peridinium" aciculifera and "Scrippsiella" hangoei constituted the sister group (88LBS, 1.00BPP) of calcareous Thoracosphaera in the T/Pf-clade (71LBS, .99BPP).

\section{Discussion}

Despite the extensive comparison of rRNA sequences, the phylogenetic relationships of the
Dinophyceae are not sufficiently resolved at present. Several strategies have been pursued to overcome this problem. The consideration of additional loci such as nuclear and mitochondrial coding genes in concatenated phylogenetic analyses has improved the resolution of molecular trees in the Dinophyceae (Hoppenrath and Leander 2010; Zhang et al. 2007, 2008), but the taxon sampling as well as the amount of genetic information is currently still limited. Moreover, chloroplast genes have been sequenced to infer the phylogenetic relationships, with unsatisfying results mainly caused by multiple endosymbiosis events in the Dinophyceae (Bhattacharya and Nosenko 2008; Howe et al. 2008; Minge et al. 2010). Another strategy to improve molecular trees is the compilation of the comprehensive rRNA sequence data presently available. A number of particular strains have been independently sequenced for the SSU, the ITS region, and / or the LSU, but they have not been brought together in a concatenated alignment yet. In this study, we have compiled all rRNA sequences of the Alveolata that span the entire SSU, the ITS region, and the first three domains of the LSU to explore the utility of this commonly used marker in phylogenetic studies. We thus present data matrices with more informative sites than any previous phylogenetic analysis of the Dinophyceae.

To test the monophyly of the Thoracosphaeraceae based on large molecular data sets has been one major goal of this study, and our results confirm and improve previous trees of calcareous dinophytes with smaller amounts of sequence data (Gottschling et al. 2005a) and / or a limited taxon sample (Tillmann et al. 2009; Zhang et al. 2007). The assumption that the Thoracosphaerales (i.e., Thoracosphaera) and the Calciodinelloideae (i.e., Scrippsiella and relatives) have to be assigned to different taxonomic units (Fensome et al. 1993; Tangen et al. 1982), implying that they are not closely related, is clearly rejected by the data presented here. The monophyly of the Thoracosphaeraceae remains, however, somewhat ambiguous, since the support is only moderate as inferred from the alignment comprising more diverse but shorter rRNA sequences. This is particularly because of the weak association of the E/Pe-clade (with calcareous Calcicarpinum bivalvum) to the other calcareous dinophytes. Species currently assigned to Peridiniopsis might also belong to this clade as it has been assumed previously based on morphology, but the extant diversity of the $\mathrm{E} / \mathrm{Pe}$-clade is otherwise highly fragmentarily investigated at present (Elbrächter et al. 2008). It remains to be determined whether 
an improved taxon sampling and future molecular studies will better enlighten the precise relationships of and within the E/Pe-clade. The vast majority of the Thoracosphaeraceae (i.e., Scrippsiella s.l. and the T/Pf-clade), however, clearly constitute a monophyletic group. The acceptance of the Pfiesteriaceae as a distinct systematic unit (Steidinger et al. 1996) would, anyhow, leave the remainders of the Thoracosphaeraceae paraphyletic.

Within the impressive diversity of the Alveolata, the potential to produce calcareous structures is restricted to (i.e., has been considered apomorphic for) the Thoracosphaeraceae, arguing for the monophyly of this group (Janofske 1992; Kohring et al. 2005; Wall and Dale 1968). Previous molecular studies have revealed, however, that a number of species with no calcareous coccoid stages known (i.e., primarily Pfiesteria and its relatives) are nested within the Thoracosphaeraceae (Gottschling et al. 2005a; Kremp et al. 2005; Tillmann et al. 2009; Zhang et al. 2007). From an evolutionary perspective, the close relationships between scrippsielloid algae and the parasites Duboscquodinium and Tintinnophagus (Coats et al. 2010) are now particularly surprising. The assumption that the potential to produce calcareous structures has arisen only once in the Dinophyceae is therefore challenged by the phylogenetic results presented here as well as by the recent observation of different calcification modes during encystment of such algae (Meier et al. 2007). It is also possible, however, that the relationships within the Thoracosphaeraceae appear still complex because of our limited knowledge about the diversity of developmental stages among (calcareous) dinophytes. More research is necessary to validate, for example, that a parasitic life style is integral part of the development of (calcareous) Calcicarpinum bivalvum (= "Pentapharsodinium" tyrrhenicum: Smith et al. 2007).

Another goal of our study has been the determination of the systematic position of Bysmatrum. The thecal plate arrangements of the strain under investigation is consistent with previous descriptions (Faust and Steidinger 1998; Murray et al. 2006; Steidinger and Balech 1977) and correspond to the typical peridinean pattern (Fensome et al. 1993; Taylor 1980). As inferred from the molecular trees, Bysmatrum does most probably not belong to the Thoracosphaeraceae as previously assumed (Steidinger and Balech 1977), but must be considered an unusual member of the Dinophyceae of uncertain systematic placement at present, presumably close to the Gonyaulacales. Our results support the assumption that the peridinean plate pattern is widespread and present in different lineages of the Dinophyceae (Taylor 2004). Therefore, it cannot be considered an apomorphic trait of the Peridiniales that seem to be a paraphyletic group, from which other lineages of the Dinophyceae have been probably derived.

The monophyly of some established systematic units such as the Dinophysiales and the Gonyaulacales are clearly supported by the molecular data presented here. The repeatedly shown molecular polyphyly of the Prorocentrales in rRNA trees (Grzebyk et al. 1998; Hoppenrath and Leander 2008), however, remains a mystery, since the group is clearly monophyletic based on morphological apomorphic traits such as a cluster of very small platelets around two pores and the lack of a girdle and sulcus. A multi-gene approach as well as a cox 1 phylogeny render the Prorocentrales monophyletic (Murray et al. 2009; Zhang et al. 2007), and the polyphyly of the Prorocentrales in rRNA trees has been explained by intrinsic inadequacies of the molecules used to resolve the phylogeny (Taylor 2004). In our molecular tree of the Alveolata, two unequal copies of rRNA genes, present on different chromosomes of Plasmodium vivax of the same individuals, illustrate this problem. Intragenomic polymorphisms of ribosomal genes have been identified in various eukaryotic lineages (GriffithsJones 2007; Le Blancq et al. 1997; Simon and Weiß 2008; Thornhill et al. 2007; Torres-Machorro et al. 2010), with putatively fatal implications for reconstructions of phylogenetic relationships. Thus, the consideration of non-orthologous sequences might explain the molecular polyphyly of the Prorocentrales, and it remains an open question, how many rRNA sequences are additionally affected in the Dinophyceae.

In conclusion, the application of long rRNA sequences helps to test hypotheses on relationships in the Dinophyceae more rigorously. Bysmatrum clearly belongs to the Dinophyceae (although the precise systematic placement cannot be determined at present), and the Thoracosphaeraceae including both calcareous and non-calcareous forms most probably constitute a monophyletic group. From a morphological perspective, putatively close relatives of the Thoracosphaeraceae such as some freshwater species of Peridinium (but not the type species P. cinctum: Calado et al. 2009; Gottschling et al. 2005a; Logares et al. 2007) and the heterotrophic Protoperidinium (Elbrächter et al. 2008) should be included in future molecular studies using long rRNA sequences. The phylogenetic trees provided 
in this study may prove helpful to revise the systematics of the Dinophyceae in general and of the Peridiniales in particular. Sequences from genes and spacers of the rRNA operon are available from less than $25 \%$ of the currently described taxa of the Dinophyceae at the generic level, and more research is necessary to improve the knowledge about their systematics and phylogenetic relationships.

\section{Methods}

Light and electron microscopy: Bysmatrum subsalsum was collected in Greece (Supplementary Material Table S1) and is currently cultivated at the universities of Thessaloniki (Department of Botany, School of Biology), Bremen (Historical Geology and Paleontology department), and Munich (Systematic Botany and Mycology department of the LMU). It grows in sterile filtrated K-Medium, specifically in 35\%o artificial seawater (hw marinemix professional, Wiegandt, Krefeld, Germany) without silicate (Keller et al. 1987) at pH 8.0-8.2, and is stored in a Percival I-36VL climate chamber (CLF PlantClimatics, Emersacker, Germany) at $23^{\circ} \mathrm{C}, 80 \mu \mathrm{mol}$ photons $\mathrm{m}^{-2} \mathrm{~s}^{-1}$, and 12:12-h light:dark photoperiod. Cells were observed in a CKX41 inverse microscope (Olympus, Hamburg, Germany).

For scanning electron microscope (SEM) studies, cells were fixed with $2,5 \%$ glutaraldehyde (Plano, Wetzler, Germany) in $0.2 \mathrm{M}$ cacodylate buffer (Roth, Karlsruhe, Germany), with $0.4 \mathrm{M}$ $\mathrm{NaCl}$ (Roth), $\mathrm{pH} 8.0$ for $1 \mathrm{~h}$, transferred in a Swinnex filter holder (Schubert \& Weiss Omnilab, München, Germany) equipped with a polycarbonate membrane with $5 \mu \mathrm{m}$ pores. Liquids were changed with a plastic syringe connected to the filter holder. The cells were washed in $75 \mathrm{mM}$ cacodylate buffer (Roth), $2 \mathrm{mM} \mathrm{MgCl}_{2}$ (Roth), $0.4 \mathrm{M} \mathrm{NaCl}$ (Roth), $\mathrm{pH} 8.0$ and distillated water, dehydrated in a graded acetone p.a. series (Roth), and critical point dried. The filters were placed on SEM stubs, and samples were sputter-coated with platinum and documented with a LEO 438 VP SEM. The Kofoid system (Fensome et al. 1993; Taylor 1980) was used for thecal plate designation.

Molecular work and phylogenetic analyses: Sequences of those Alveolata that comprised the SSU, 5.8S rRNA (including the ITSs), and the first three domains of the LSU were downloaded from GenBank. Fresh material (clonal cultures, mostly cultivated at the University of Bremen, Germany) was used for sequencing of five species of the Thoracosphaeraceae plus Bysmatrum. To exclude the possibility of contaminations, DNA isolation and sequencing were independently performed in the labs of MG, UJ, JP, and MS, following standard protocols that are described in detail in Gottschling and Plötner (2004). The specific primers for amplification used in this study are listed in Table S2. In total, 160 terminal taxa were investigated in this study (Table S1).

The consideration particularly of the highly divergent ITS sequences over a broad taxonomic range such as the dinophytes should be treated with caution, and we explored the possible negative effects for our phylogenetic reconstructions by RY-coding, excluding phylogenetically ambiguous positions, using different alignment programs, and applying an infinite mixture model to the data (see the Supplementary Materials for details). For the main part of our study, sequences of two different taxon samples were aligned using 'MUSCLE' v3.6 (Edgar
2004; http://www.drive5.com/MUSCLE/downloads.htm), with the default settings: The first taxon sample included all sequences of the Alveolata available comprising the complete SSU, the complete ITS region (including the 5.8S rRNA), and the first three domains of the LSU; the other data matrix used shorter LSU sequences in order to include a broader taxon sample of the Dinophyceae. The alignments were partitioned into three parts (for details see Tables S3-S4 in the Supplementary Material, and all final data matrices are available under doi:10.5061/dryad.d1vg6 or from MG upon request).

Phylogenetic analyses were run using distinct models / data partitions, with individual per partition branch length optimisation. Calculations were carried out by using the resources of the Leibniz Rechenzentrum (LRZ, Munich; linux cluster HLRB-II) and of the SGI system (Zuse Institute Berlin, ZIB) being one half of the North German High Performance Computer (HLRN). Maximum Likelihood-based analyses were conducted using the PTHREADS version of 'RAxML' VII (Stamatakis 2006; Stamatakis et al. 2008; http://www.phylo.org/portal/Home.do) and applying the GTR substitution matrix. To determine best fitted ML-trees, we executed 10-tree searches from distinct random stepwise addition sequence Maximum Parsimony starting trees and 10,000 non-parametric bootstrap replicates. Bayesian analyses were performed with 'MrBayes' v3.1.2 (Huelsenbeck and Ronquist 2001; http://www.mrbayes.csit.fsu.edu/) under the GTR $+\Gamma$ substitution model using the random-addition-sequence method with 10 replicates. We ran two independent analyses of four chains (one cold and three heated) with 20,000,000 cycles, sampled every 1,000 th cycle, with an appropriate burnin $(10 \%)$ as inferred from the evaluation of the trace files using Tracer v1.5 (http://tree.bio.ed.ac.uk/software/tracer/). The statistical support values were drawn on the best scoring ML-trees.

\section{Acknowledgements}

This study was performed together with Georgios Nikolaidis (Department of Botany, School of Biology, Aristotle University of Thessaloniki), who died during the course of the project. We are deeply saddened by the loss of our good friend and colleague. We would like to express our gratitude to Michael Ott (Munich) for help with using the HPC servers of the LMU. Hervé Philippe (Montreal) and two anonymous reviewers provided valuable suggestions to improve a previous draft of the manuscript which is acknowledged here. We thank the Deutsche Forschungsgemeinschaft (grants KE 322/36, PL 213/4, RI 1738/5, and WI 725/25) and the Münchener Universitätsgesellschaft for financial support.

\section{Appendix A. Supplementary data}

Supplementary data associated with this article can be found, in the online version, at doi:10.1016/j.protis.2011.06.003. 


\section{References}

Bhattacharya D, Nosenko T (2008) Endosymbiotic and horizontal gene transfer in chromalveolates. J Phycol 44:7-10

Calado AJ, Craveiro SC, Daugbjerg N, Moestrup Ø (2009) Description of Tyrannodinium gen. nov., a freshwater dinoflagellate closely related to the marine Pfiesteria-like species. J Phycol 45:1195-1205

Coats DW, Kim S, Bachvaroff TR, Handy SM, Delwiche CF (2010) Tintinnophagus acutus n. g., n. sp. (Phylum Dinoflagellata), an ectoparasite of the ciliate Tintinnopsis cylindrica Daday 1887 , and its relationship to Duboscquodinium collini Grassé 1952. J Eukaryot Microbiol 57:468-482

D’Onofrio G, Marino D, Bianco L, Busico E, Montresor M (1999) Toward an assessment on the taxonomy of dinoflagellates that produce calcareous cysts (Calciodinelloideae, Dinophyceae): A morphological and molecular approach. J Phycol 35:1063-1078

Daugbjerg N, Hansen G, Larsen J, Moestrup Ø (2000) Phylogeny of some of the major genera of dinoflagellates based on ultrastructure and partial LSU rDNA sequence data, including the erection of three new genera of unarmoured dinoflagellates. Phycologia 39:302-317

Dodge JD (1966) The Dinophyceae. In Godward MBE (ed) The chromosomes of the algae. St. Martin's Press, New York, pp 96-115

Edgar RC (2004) MUSCLE: A multiple sequence alignment method with reduced time and space complexity. BMC Bioinformatics 5:1-19

Elbrächter M, Gottschling M, Hildebrand-Habel T, Keupp H, Kohring R, Lewis J, Meier KJS, Montresor M, Streng M, Versteegh GJM, Willems H, Zonneveld KAF (2008) Establishing an Agenda Calcareous Dinoflagellate Research (Thoracosphaeraceae, Dinophyceae) including a nomenclatural synopsis of generic names. Taxon 57:1289-1303

Faust MA, Steidinger KA (1998) Bysmastrum gen. nov. (Dinophyceae) and three new combinations for benthic scrippsielloid species. Phycologia 37:47-52

Fensome RA, Saldarriaga JF, Taylor FJR (1999) Dinoflagellate phylogeny revisited: Reconciling morphological and molecular based phylogenies. Grana 38:66-80

Fensome RA, Taylor FJR, Norris G, Sarjeant WAS, Wharton DI, Williams GL (1993) A Classification of Living and Fossil Dinoflagellates. Micropaleontology Special Publication no. 7. New York: American Museum of Natural History, 245 pp.

Gottschling M, Plötner J (2004) Secondary structure models of the nuclear Internal Transcribed Spacer regions and 5.8S rRNA in Calciodinelloideae (Peridiniaceae) and other dinoflagellates. Nucleic Acids Res 32:307-315

Gottschling M, Keupp H, Plötner J, Knop R, Willems H, Kirsch M (2005a) Phylogeny of calcareous dinoflagellates as inferred from ITS and ribosomal sequence data. Mol Phylogenet Evol 36:444-455

Gottschling M, Knop R, Plötner J, Kirsch M, Willems M, Keupp H (2005b) A molecular phylogeny of Scrippsiella sensu lato (Calciodinellaceae, Dinophyta) with interpretations on morphology and distribution. Eur J Phycol 40:207-220
Griffiths-Jones S (2007) Annotating noncoding RNA genes. Annu Rev Genomics Hum Genet 8:279-298

Grzebyk D, Sako Y, Berland B (1998) Phylogenetic analysis of nine species of Prorocentrum (Dinophyceae) inferred from $18 \mathrm{~S}$ ribosomal DNA sequences, morphological comparisons, and description of Prorocentrum panamensis, sp. nov. J Phycol 34:1055-1068

Harper JT, Waanders E, Keeling PJ (2005) On the monophyly of chromalveolates using a six-protein phylogeny of eukaryotes. Int J Syst Evol Microbiol 55:487-496

Hoppenrath M, Leander BS (2008) Morphology and molecular phylogeny of a new marine sand-dwelling Prorocentrum species, $P$. tsawwassenense (Dinophyceae, Prorocentrales), from British Columbia, Canada. J Phycol 44:451-466

Hoppenrath M, Leander BS (2010) Dinoflagellate phylogeny as inferred from Heat Shock Protein 90 and ribosomal gene sequences. Plos One 5:e13220, doi:10.1371/journal.pone.0013220

Howe CJ, Barbrook AC, Nisbet RER, Lockhart PJ, Larkum AWD (2008) The origin of plastids. Philos Trans R Soc B-Biol Sci 363:2675-2685

Huelsenbeck JP, Ronquist F (2001) MRBAYES: Bayesian inference of phylogenetic trees. Bioinformatics 17:754-755

Janofske D (1992) Kalkiges Nannoplankton, insbesondere kalkige Dinoflagellaten-Zysten der alpinen Ober-Trias: Taxonomie, Biostratigraphie und Bedeutung für die Phylogenie der Peridiniales. Berl Geowiss Abh (E) 4:1-53

John U, Fensome RA, Medlin LK (2003) The application of a molecular clock based on molecular sequences and the fossil record to explain biogeographic distributions within the Alexandrium tamarense "species complex" (Dinophyceae). Mol Biol Evol 20:1015-1027

Keller MD, Selvin RC, Claus W, Guillard RRL (1987) Media for the culture of oceanic ultraphytoplankton. J Phycol 23: 633-638

Kohring R, Gottschling M, Keupp H (2005) Examples for character traits and palaeoecological significance of calcareous dinoflagellates. Paläontol Z 79:79-91

Kremp A, Elbrächter M, Schweikert M, Wolny JL, Gottschling M (2005) Woloszynskia halophila (Biecheler) comb. nov.: A bloom-forming cold-water dinoflagellate cooccurring with Scrippsiella hangoei (Dinophyceae) in the Baltic Sea. J Phycol 41:629-642

Le Blancq SM, Khramtsov NV, Zamani F, Upton SJ, Wu TW (1997) Ribosomal RNA gene organization in Cryptosporidium parvum. Mol Biochem Parasitol 90:463-478

Leander BS, Keeling PJ (2004) Early evolutionary history of dinoflagellates and apicomplexans (Alveolata) as inferred from hsp90 and actin phylogenies. J Phycol 40:341-350

Logares R, Shalchian-Tabrizi K, Boltovskoy A, Rengefors K (2007) Extensive dinoflagellate phylogenies indicate infrequent marine-freshwater transitions. Mol Phylogenet Evol 45:887-903

Meier KJS, Young JR, Kirsch M, Feist-Burkhardt S (2007) Evolution of different life-cycle strategies in oceanic calcareous dinoflagellates. Eur J Phycol 42:81-89 
Minge MA, Shalchian-Tabrizi K, Torresen OK, Takishita K, Probert I, Inagaki Y, Klaveness D, Jakobsen KS (2010) A phylogenetic mosaic plastid proteome and unusual plastid-targeting signals in the green-colored dinoflagellate Lepidodinium chlorophorum. BMC Evol Biol 10:191

Montresor M, Sgrosso S, Procaccini G, Kooistra WHCF (2003) Intraspecific diversity in Scrippsiella trochoidea (Dinophyceae): Evidence for cryptic species. Phycologia 42:56-70

Moore RB, Obornik M, Janouskovec J, Chrudimsky T, Vancova M, Green DH, Wright SW, Davies NW, Bolch CJS, Heimann K, Slapeta J, Hoegh-Guldberg O, Logsdon JM, Carter D.A. (2008) A photosynthetic alveolate closely related to apicomplexan parasites. Nature 451: 959-963.

Morden CW, Sherwood AR (2002) Continued evolutionary surprises among dinoflagellates. Proc Natl Acad Sci USA 99:11558-11560

Moreno Díaz de la Espina S, Alverca E, Cuadrado A, Franca S (2005) Organization of the genome and gene expression in a nuclear environment lacking histones and nucleosomes: The amazing dinoflagellates. Eur J Cell Biol 84:137-149

Murray S, Hoppenrath M, Larsen J, Patterson DJ (2006) Bysmatrum teres sp. nov., a new sand-dwelling dinotlagellate from north-western Australia. Phycologia 45:161-167

Murray S, Ip CL, Moore R, Nagahama Y, Fukuyo Y (2009) Are prorocentroid dinoflagellates monophyletic? A study of 25 species based on nuclear and mitochondrial genes. Protist 160:245-264

Rill RL, Livolant F, Aldrich HC, Davidson MW (1989) Electron microscopy of liquid crystalline DNA: Direct evidence for cholesteric-like organization of DNA in dinoflagellate chromosomes. Chromosoma 98:280-286

Rizzo PJ (2003) Those amazing dinoflagellate chromosomes. Cell Res 13:215-217

Saldarriaga JF, Taylor FJR, Cavalier-Smith T, MendenDeuerd S, Keeling PJ (2004) Molecular data and the evolutionary history of dinoflagellates. Eur J Protistol 40:85-111

Shalchian-Tabrizi K, Skånseng M, Ronquist F, Klaveness D, Bachvaroff TR, Delwiche CF, Botnen A, Tengs T, Jakobsen KS (2006) Heterotachy processes in rhodophyte-derived secondhand plastid genes: Implications for addressing the origin and evolution of dinoflagellate plastids. Mol Biol Evol 23:1504-1515

Simon UK, Weiß M (2008) Intragenomic variation of fungal ribosomal genes is higher than previously thought. Mol Biol Evol 25:2251-2254

Smith K, Dodson M, Santos S, Gast R, Rogerson A, Sullivan B, Moss AG (2007) Pentapharsodinium tyrrhenicum is a parasitic dinoflagellate of the ctenophore Mnemiopsis leidyi. J Phycol 43:119

Stamatakis A (2006) RAxML-VI-HPC: Maximum likelihoodbased phylogenetic analyses with thousands of taxa and mixed models. Bioinformatics 22:2688-2690
Stamatakis A, Hoover P, Rougemont J (2008) A rapid bootstrap algorithm for the RAxML web-servers. Syst Biol 57:758-771

Steidinger KA, Balech E (1977) Scrippsiella subsalsa (Ostenfeld) comb. nov. (Dinophyceae) with a discussion on Scrippsiella. Phycologia 16:69-73

Steidinger KA, Burkholder JM, Glasgow Jr HB, Hobbs CW, Garrett JK, Truby EW, Noga EJ, Smith SA (1996) Pfiesteria piscicida gen. et sp. nov. (Pfiesteriaceae fam. nov.), a new toxic dinoflagellate with a complex life cycle and behavior. J Phycol 32:157-164

Tangen K, Brand LE, Blackwelder PL, Guillard RRL (1982) Thoracosphaera heimii (Lohmann) Kamptner is a dinophyte: Observations on its morphology and life cycle. Mar Micropaleontol 7:193-212

Taylor FJR (1980) On dinoflagellate evolution. Biosystems 13:65-108

Taylor FJR (2004) Illumination or confusion? Dinoflagellate molecular phylogenetic data viewed from a primarily morphological standpoint. Phycol Res 52:308-324

Ten-Hage L, Quod J-P, Turquet J, Couté A (2001) Bysmatrum granulosum sp. nov., a new benthic dinoflagellate from the southwestern Indian Ocean. Eur J Phycol 36: 129-135

Thornhill DJ, LaJeunesse TC, Santos SR (2007) Measuring rDNA diversity in eukaryotic microbial systems: How intragenomic variation, pseudogenes, and PCR artifacts confound biodiversity estimates. Mol Ecol 16:5326-5340

Tillmann U, Elbrächter M, Krock B, John U, Cembella A (2009) Azadinium spinosum gen. et sp. nov. (Dinophyceae) identified as a primary producer of azaspiracid toxins. Eur $\mathrm{J}$ Phycol 44:63-79

Torres-Machorro AL, Hernandez R, Cevallos AM, LopezVillasenor I (2010) Ribosomal RNA genes in eukaryotic microorganisms: Witnesses of phylogeny? FEMS Microbiol Rev 34:59-86

Wall D, Dale B (1968) Quaternary calcareous dinoflagellates (Calciodinellideae) and their natural affinities. J Paleontol 42:1395-1408

Yoon HS, Hackett JD, Dolah FMV, Nosenko T, Lidie KL, Bhattacharya D (2005) Tertiary endosymbiosis driven genome evolution in dinoflagellate algae. Mol Biol Evol 22: 1299-1308

Zhang H, Bhattacharya D, Lin S (2007) A three-gene dinoflagellate phylogeny suggests monophyly of Prorocentrales and a basal position for Amphidinium and Heterocapsa. J Mol Evol 65:463-474

Zhang H, Bhattacharya D, Maranda L, Lin SJ (2008) Mitochondrial cob and cox 1 genes and editing of the corresponding mRNAs in Dinophysis acuminata from Narragansett Bay, with special reference to the phylogenetic position of the genus Dinophysis. App Environm Microbiol 74:1546-1554

Available online at www.sciencedirect.com 